\title{
The Prevalence and Diagnostic Significance of Eosinophilic Pleural Effusions: A Meta-Analysis and Systematic Review
}

\author{
Yuji Oba Tareq Abu-Salah \\ University of Missouri, Columbia, Mo., USA
}

\section{Key Words}

Pleural fluid · Pleural fluid eosinophilia

\begin{abstract}
Background: Eosinophilic pleural effusion (EPE) is defined by an eosinophil count of $\geq 10 \%$ in the pleural fluid and often caused by air or blood in the pleural space. The diagnostic significance of EPEs is still a matter of debate. Objective: The objective of this study was to systematically review the medical literature to evaluate the diagnostic significance of EPEs. Methods: Electronic databases were searched from 1950 to April 2010 to perform a meta-analysis. Data were extracted using standardized forms, and pooled odds ratios with $95 \%$ confidence intervals were calculated. A logistic regression analysis was also performed to evaluate the association between the pleural eosinophil counts and the likelihood of underlying causes of EPEs. Results: We identified a total of 687 cases of EPE. The most common cause of EPEs was malignancy (26\%) followed by idiopathic (25\%) and parapneumonic (13\%) effusions. The likelihood of malignancy or tuberculosis was somehow lower in EPEs than in non-EPEs, but the differences were not statistically significant. The prevalence of malignancy was significantly lower in the group of patients that required a pathologic confirmation
\end{abstract}

(21 vs. 30\%; $p=0.01$ ). The likelihood of malignancy was inversely correlated with the pleural fluid eosinophil counts. The likelihood of idiopathic effusion was significantly higher in EPEs than in non-EPEs. Conclusions: Malignancy was the most common cause of EPEs. EPEs appeared to be a negative predictor of malignancy when a pleural fluid eosinophil count was extremely high. EPEs were more likely to be idiopathic as compared with non-EPEs.

Copyright $\odot 2011$ S. Karger AG, Basel

\section{Introduction}

Eosinophilic pleural effusion (EPE) is defined by an eosinophil count of $\geq 10 \%$ in the pleural fluid and accounts for approximately $10 \%$ of exudative pleural effusions [1]. The pathogenesis of EPEs is poorly understood and likely multifactorial. Animal and human studies suggest an important role of interleukin- 5 in their pathogenetic pathways $[2,3]$.

The causes of EPEs include but are not limited to the presence of air or blood in the pleural space, malignancy, infections (bacteria, fungi, mycobacteria, parasites and viruses), pulmonary embolism, drug reactions and asbestos exposure.

\section{KARGER}

Fax +41613061234

E-Mail karger@karger.ch

www.karger.com
(C) 2011 S. Karger AG, Basel

0025-7931/12/0833-0198\$38.00/0

Accessible online at:

www.karger.com/res
Yuji Oba, MD

University of Missouri

1 Hospital Drive

Columbia, MO 65212 (USA)

Tel. +1 573882 8583, E-Mail obay@ health.missouri.edu 
The diagnostic significance of EPEs is still a matter of debate. It was once believed that malignancy or tuberculosis was an unlike cause of EPEs [4], but recent studies argued against such a notion $[5,6]$. A possible explanation for such disparity was that the study population was different in each study and the varying disease spectrum of EPEs was just a reflection of the population studied.

Therefore, we hypothesized that the disease spectrum of EPEs was not different from that of non-EPEs. The objective of this study was to systematically review the medical literature to evaluate the diagnostic significance of EPEs.

\section{Materials and Methods}

\section{Search Strategy}

Two authors independently searched the National Library of Medicine's Medline database for studies in the English language published from 1950 to April 2010 by using the following headings and keywords of the Medical Subject Headings: pleural effusion or pleurisy or pleura AND eosinophils or eosinophilia. We searched the Cochrane Central Register of Controlled Trials, Cochrane Database of Systematic Reviews, Database of Abstracts of Reviews of Effects, Biologic Abstracts and Cumulative Index to Nursing and Allied Health Literature. All searches were restricted to human studies including only adults ( $\geq 19$ years). Bibliographies of all selected articles and review articles that included information on EPEs were reviewed for other relevant articles.

\section{Study Selection}

Studies relevant to the prevalence and diagnostic significance of EPEs were included if the following criteria were met: (1) if at least more than 5 of the original cases of EPE, which is defined by an eosinophil count of $\geq 10 \%$ in the pleural fluid, were reported; (2) a clinical study with the Strengthening the Reporting of Observational Studies in Epidemiology (STROBE) score [7] of at least 5; (3) if the etiology of EPEs was described in all patients. The results from a study that used a different cutoff point (e.g., an eosinophil count of $\geq 5 \%$ ) were modified using the $10 \%$ cutoff and included in the analysis.

\section{Assessment of Study Quality}

The quality of included studies was assessed with the STROBE criteria. Each study was given a score on a scale from 1 to 22 , reflecting how many of the 22 STROBE items were complied with (with each item being given equal weighting). This score was termed 'STROBE score'.

\section{Data Extraction}

The etiology of EPEs was classified into the following categories: malignancy, parapneumonic effusion, tuberculosis, pulmonary embolism, transudate (congestive heart failure, kidney disease and hepatic cirrhosis), collagen vascular disease (CVD), idiopathic effusion, pleural air/blood (hemothorax, post-trauma, thoracotomy, pneumothorax and previous thoracentesis), and others. Diagnostic criteria for the above disorders were extracted from the included studies and tabulated. Cases were reclassified as pleural air/blood, whenever possible, if EPE was found only on repeated thoracentesis or was associated with chest trauma or pneumothorax.

We performed a separate analysis examining the correlation between pleural fluid eosinophil counts and the likelihood of underlying causes of EPEs. We extracted cases of EPE from the medical literature in which a pleural fluid eosinophil count and an underlying etiology were individually reported.

\section{Statistical Analysis}

The pooled prevalence of EPEs among all pleural effusions was calculated from included studies, and it was reported along with its $95 \%$ confidence interval (CI). We examined the change in the prevalence of underlying causes over time using a cumulative meta-analysis [8]. Studies were sequentially added by year of publication to a random-effects model after excluding cases associated with pleural air/blood.

To determine the diagnostic significance of EPEs, the pooled prevalence of underlying causes of EPEs was calculated and compared with that of non-EPEs. The calculations were performed after excluding the cases of transudate and pleural air/blood. The results were expressed as odds ratios (ORs) along with their $95 \%$ CIs.

A $\mathrm{Z}$ test was performed to examine the overall effect. We tested heterogeneity between trials with $\mathrm{I}^{2}$ statistic, with $\mathrm{I}^{2}>50 \%$ indicating significant heterogeneity [9]. A random-effects model was used for the meta-analysis if significant heterogeneity was detected. A fixed effects model was used otherwise [10].

Sensitivity analyses were performed to assure the robustness of the results by excluding studies individually from the pooled analyses and using a random- or fixed-effects model, relative risks and risk differences [11].

A logistic regression analysis was performed to examine the correlation between pleural fluid eosinophil counts and the probability of underlying causes of EPEs. A receiver operator characteristic curve was constructed to summarize the sensitivity and specificity estimates. The standard $\chi^{2}$ test was used for the comparison of 2 data points. All reported p values are 2 -sided. $p$ values $<0.05$ were considered to indicate statistical significance. The data analysis was performed using meta-analysis software (StatsDirect, StatsDirect Ltd., Cheshire, UK).

\section{Results}

\section{Studies and Cases Identified}

The electronic database searches identified 411 citations. Initially, 30 studies were considered potentially relevant. After a more detailed review, an additional 15 papers did not meet the inclusion criteria and were excluded. The remaining 15 studies were reviewed [1, 5, 6, 12-23] for duplicate publications. We did not find any duplicate publications. A non-electronic search identified 2 studies that met our inclusion criteria $[24,25]$. We included a total of 17 studies in our analysis (fig. 1). 


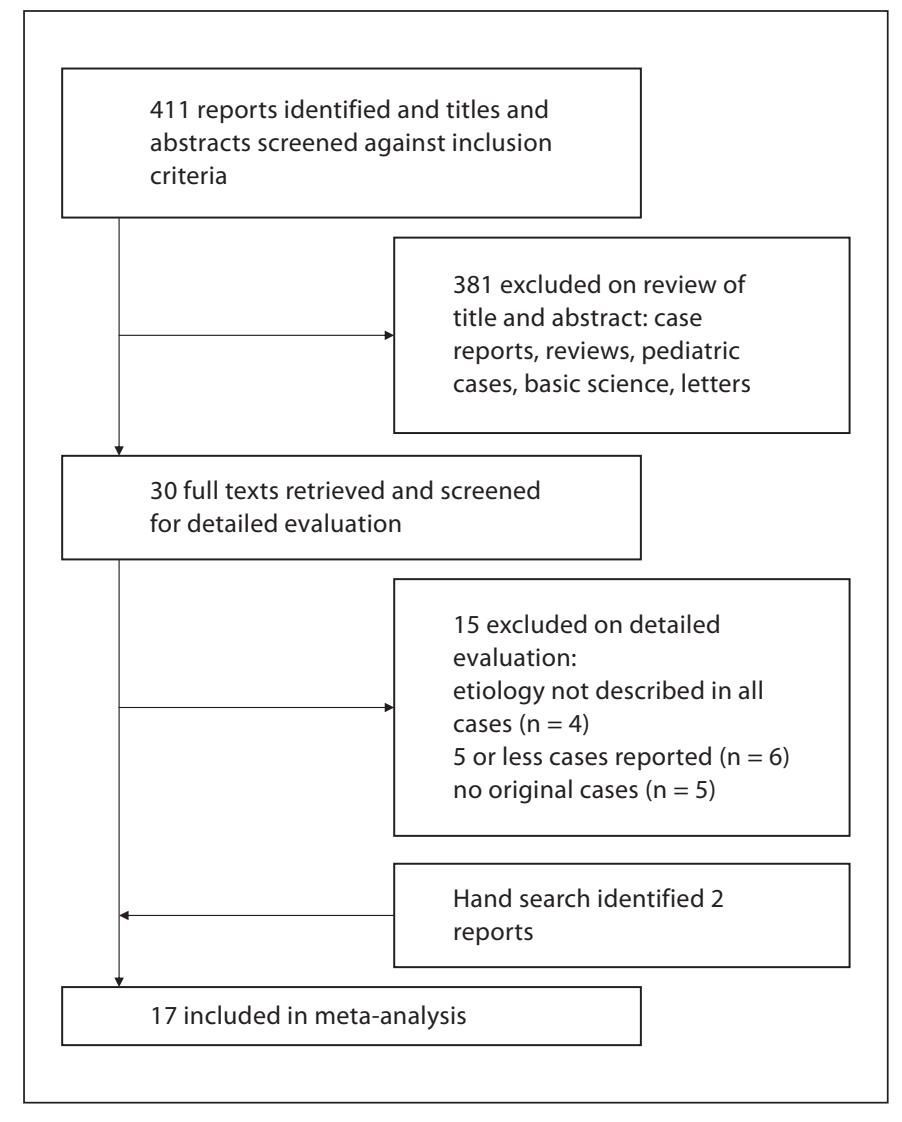

Fig. 1. Flow of study selection.

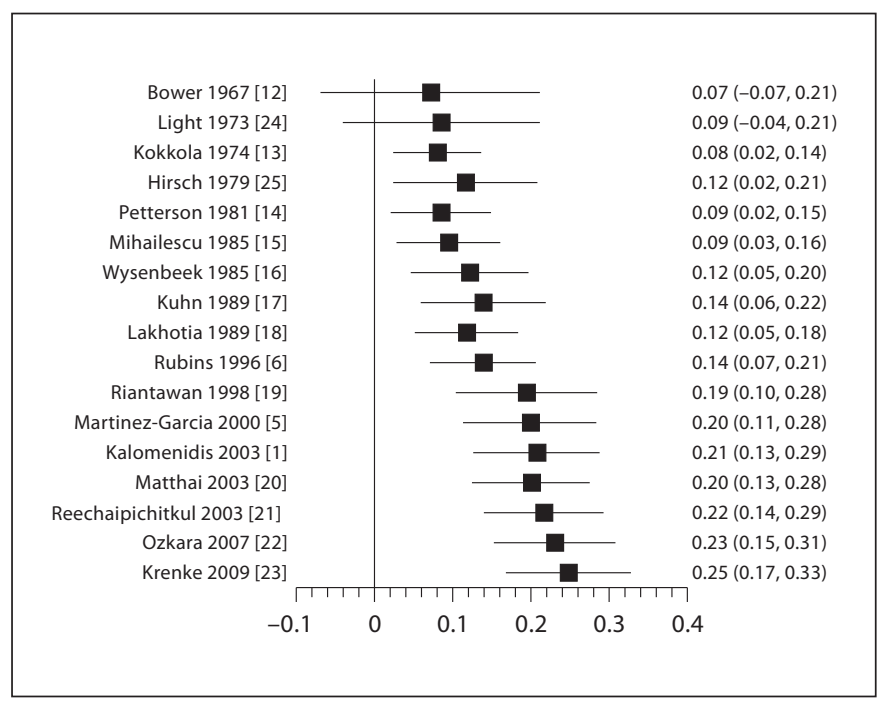

Fig. 2. Cumulative prevalence of malignancy in cases with EPEs. Each later estimate is a pooled estimate of all previous studies. Data are ORs, with confidence limits in parentheses.
The characteristics of included studies are shown in table 1. Six hundred and ninety-two cases of EPE were extracted. Five cases, reported by Mihailescu and Micu [15], with a pleural fluid eosinophil count $>5$ but $<10 \%$ were excluded. Then, a total of 687 cases were included in our analysis.

Eight studies reported the cases of EPE with the first thoracentesis only $[5,6,14,18-20,23,25]$. Cases of EPE on repeated thoracentesis were reclassified as pleural air/ blood whenever possible. However, this reclassification was not possible in 4 studies because of lack of information $[1,13,15,22]$.

The prevalence of EPEs in all pleural effusions was reported in 12 studies [5, 13-20, 22-24]. The pooled prevalence of EPEs was 9\% (random-effects model, 95\% CI $7-10$ ). The mean age of patients (56 years, range $48-63$ ) was reported in 6 studies [14, 19, 20-23]. The proportion of male patients (71\%, range 45-100) was reported in 9 studies [6, 12-14, 20-23]. The mean pleural fluid eosinophil count (27\%, range $21-40)$ was reported in 12 studies $[12,14-24]$.

The quality of included studies was variable and their quality score ranged from 5 to 17 with a median score of 13 (the maximum possible score was 22) (table 1, Appendix 1). The diagnostic criteria used in the included studies for the underlying causes of EPEs are summarized in table 2 .

The most common cause of EPEs was malignancy (26\%) followed by idiopathic (25\%) and parapneumonic (13\%) effusions, pleural air/blood (13\%), tuberculosis (7\%), transudate (7\%), other (6\%) and CVD (3\%) (table 3). Three studies excluded cases of EPE resulting from pleural air/blood [5, 18, 19]. The pooled prevalence of EPEs associated with pleural air/blood was 15\% when these studies were excluded. When cases of pleural air/blood were excluded from all studies, the prevalence of malignancy, idiopathic and parapneumonic effusions, tuberculosis, transudate, others and CVD was $30,29,14,8,7$, 4 and $4 \%$, respectively.

Eight studies reported the underlying causes of nonEPEs and EPEs. A total of 1,810 and 184 patients with non-EPE and EPE were reported in these studies, respectively. Cases associated with a transudate and pleural air/blood consisted of 17 and $0.2 \%$ of non-EPEs and 5 and $0.5 \%$ of EPEs, respectively. The prevalence of individual causes in non-EPEs and EPEs is shown in table 4 .

We identified 144 cases of EPE in which an underlying cause and a pleural fluid eosinophil count were individually reported [15, 17, 18, 24, 26-29]. They consisted of 22 
Table 1. Characteristics of included studies

\begin{tabular}{|c|c|c|c|c|c|c|}
\hline Study, year & Country & Type of study & $\begin{array}{l}\text { Number } \\
\text { of patients } \\
\text { with EPE }\end{array}$ & $\begin{array}{l}\text { Total number } \\
\text { of patients } \\
\text { with PF }\end{array}$ & $\begin{array}{l}\text { First thora- } \\
\text { centesis } \\
\text { only }\end{array}$ & $\begin{array}{l}\text { STROBE } \\
\text { quality } \\
\text { score }^{1}\end{array}$ \\
\hline Bower [12], 1967 & USA & retrospective & 21 & NR & adjusted $^{2}$ & 10 \\
\hline Light et al. [24], 1973 & USA & prospective & 8 & 182 & adjusted $^{2}$ & 13 \\
\hline Kokkola and Valta [13], 1974 & Finland & retrospective & 78 & 476 & unclear & 11 \\
\hline Hirsch et al. [25], 1979 & France & prospective & 23 & 270 & yes & 13 \\
\hline Pettersson and Riska [14], 1981 & Finland & prospective & 26 & 140 & yes & 13 \\
\hline Mihailescu and Micu [15], 1985 & Romania & retrospective & $11^{3}$ & 248 & unclear & 8 \\
\hline Wysenbeek et al. [16], 1985 & Israel & retrospective & 36 & NR & adjusted $^{2}$ & 13 \\
\hline Kuhn et al. [17], 1989 & Switzerland & prospective & 22 & 224 & adjusted $^{2}$ & 17 \\
\hline Lakhotia et al. [18], 1989 & India & prospective & 18 & 162 & yes & 11 \\
\hline Rubins and Rubins [6], 1996 & USA & prospective & 44 & NR & yes & 18 \\
\hline Riantawan et al. [19], 1998 & Thailand & prospective & 31 & 405 & yes & 14 \\
\hline Martinez-Garcia et al. [5], 2000 & Spain & retrospective & 45 & 358 & yes & 14 \\
\hline Kalomenidis and Light [1], 2003 & USA & review with original data & 53 & NR & unclear & 5 \\
\hline Matthai and Kini [20], 2003 & India & prospective & 26 & 444 & yes & 12 \\
\hline \multicolumn{7}{|l|}{ Reechaipichitkul and } \\
\hline Chuesakoolvanich [21], 2003 & Thailand & retrospective & 50 & NR & adjusted $^{2}$ & 15 \\
\hline Ozkara et al. [22], 2007 & Turkey & retro- and prospective & 60 & 697 & $\mathrm{no}^{4}$ & 12 \\
\hline Krenke et al. [23], 2009 & Poland & retrospective & 135 & 1,868 & yes & 13 \\
\hline
\end{tabular}

$\mathrm{PF}=$ Pleural fluid; NR = not reported. ${ }^{1}$ Range $0-22 ; 22$ indicates the highest quality. ${ }^{2}$ Cases of EPE only on repeated thoracentesis were reclassified as pleural air/blood (see table 2 for details). ${ }^{3}$ Five cases with pleural fluid eosinophil count $>5$ but $<10 \%$ were excluded. ${ }^{4}$ Seven patients had EPE only on repeated thoracentesis, but they were unadjustable due to lack of information.

cases of malignancy (15\%), 27 cases of parapneumonic effusion (19\%), 19 cases of tuberculosis (13\%), 7 cases of pulmonary embolism (5\%), 6 cases of CVD (4\%), 4 cases of transudate (3\%), 11 cases of other causes ( $8 \%), 10$ cases of pleural air/blood (7\%) and 38 cases of idiopathic pleural fluid (26\%). The mean \pm standard deviation of the eosinophil count was $37 \pm 21 \%$.

\section{Malignancy}

The cumulative prevalence of malignancy among EPEs has gradually increased over the last 4 decades from $7 \%$ (95\% CI -7 to 21 ) to $25 \%$ (95\% CI 17-33) (fig. 2). The diagnosis of malignancy required a pathological confirmation in some studies but not in others (table 3). The prevalence of malignancy was significantly lower in the group of patients that required a pathologic confirmation ( 21 vs. $30 \% ; \mathrm{p}=0.01$ ).

Eight studies reported the prevalence of malignant pleural effusions in EPEs and non-EPEs [5, 14, 15, 17-19]. The prevalence of malignancy was lower in EPEs than in non-EPEs except in 1 study [19] (fig. 3). The odds of malignancy in EPEs, as compared with non-EPEs, was 0.63 (95\% CI 0.28-1.47; $\mathrm{p}=0.29)$. The odds ratio $(\mathrm{OR})$ became

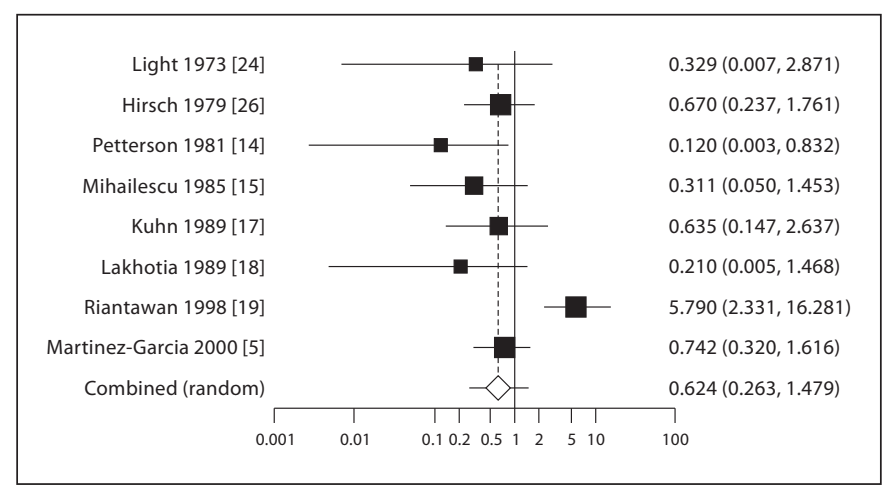

Fig. 3. OR meta-analysis plot (random-effects model). Pooled OR for malignancy in EPEs as compared with non-EPEs. Test for heterogeneity: $\chi^{2}=1.12$ (d.f. $\left.=1\right) ; \mathrm{I}^{2}=74.4 \%$. Data are ORs, with confidence limits in parentheses.

statistically significant when a study by Riantawan et al. [19] was excluded from the analysis (OR 0.51, 95\% CI $0.32-0.78 ; \mathrm{p}=0.001$ ).

The logistic regression analysis revealed a significant correlation between the pleural fluid eosinophil counts 
Table 2. Diagnostic criteria used in the included studies

\begin{tabular}{|c|c|c|c|c|c|c|c|}
\hline Study & $\begin{array}{l}\text { Malig- } \\
\text { nancy }\end{array}$ & $\begin{array}{l}\text { Para- } \\
\text { pneumonic } \\
\text { effusion }\end{array}$ & ТВ & $\mathrm{PE}$ & CVD & Exudate & $\begin{array}{l}\text { Duration of } \\
\text { follow-up for } \\
\text { idiopathic cases }\end{array}$ \\
\hline Bower [12], 1967 & Path & ND & N/A & ND & ND & $\begin{array}{l}\text { PF protein } \\
>3 \mathrm{~g} / \mathrm{dl}\end{array}$ & $\begin{array}{l}3 \text { years for } \\
\text { TB suspects }\end{array}$ \\
\hline Light et al. [24], 1973 & Path & ClinRadMicro & MicroPath & $\mathrm{Rad}$ & Clin & ND & ND \\
\hline Kokkola and Valta [13], 1974 & Path & ClinRadMicro & MicroPath & N/A & Clin $^{1}$ & ND & ND \\
\hline Hirsch et al. [25], 1979 & ClinPath & ClinRadMicro & MicroPath & N/A & N/A & $\begin{array}{l}\mathrm{PF} \text { protein } \\
>3 \mathrm{~g} / \mathrm{dl}\end{array}$ & ND \\
\hline Pettersson and Riska [14], 1981 & Path & ClinRadMicro & $\begin{array}{l}\text { CR or } \\
\text { MicroPath }\end{array}$ & $\mathrm{N} / \mathrm{A}$ & & LC & ND \\
\hline Mihailescu and Micu [15], 1985 & ND & ND & ND & ND & ND & ND & ND \\
\hline Wysenbeek et al. [16], 1985 & $\mathrm{Clin}^{2}$ & $\mathrm{ND}$ & ND & ND & $\mathrm{ND}$ & $\mathrm{ND}$ & ND \\
\hline Kuhn et al. [17], 1989 & Path & \multicolumn{6}{|c|}{ Diagnoses were extracted from retrospective review of clinical records ${ }^{3}$} \\
\hline Lakhotia et al. [18], 1989 & \multicolumn{5}{|c|}{$\begin{array}{l}\text { Diagnoses were made based on clinical, radiographic, } \\
\text { laboratory and histopathologic findings }{ }^{3}\end{array}$} & $\begin{array}{l}\text { PF: serum } \\
\text { protein }>0.5\end{array}$ & 1 year \\
\hline Rubins and Rubins [6], 1996 & ClinPath & \multicolumn{4}{|c|}{$\begin{array}{l}\text { Diagnoses were determined by the treating } \\
\text { physicians based on clinical, radiographic, } \\
\text { laboratory and histopathologic findings }{ }^{3}\end{array}$} & LC & ND \\
\hline Riantawan et al. [19], 1998 & Path & ClinRadMicro & MicroPath & ND & $\operatorname{Clin}^{4}$ & ND & $>6$ months \\
\hline Martinez-Garcia et al. [5], 2000 & Path & ClinRadMicro & MicroPath & ND & ND & LC & $>18$ months $^{5}$ \\
\hline Kalomenidis and Light [1], 2003 & ND & $\mathrm{ND}$ & ND & N/A & N/A & ND & ND \\
\hline Matthai and Kini [20], 2003 & Path & \multicolumn{3}{|c|}{$\begin{array}{l}\text { Diagnoses were determined by the treating } \\
\text { physicians based clinical, radiographic, } \\
\text { laboratory and histopathologic findings }{ }^{5}\end{array}$} & & LC & ND \\
\hline $\begin{array}{l}\text { Reechaipichitkul and } \\
\text { Chuesakoolvanich [21], } 2003\end{array}$ & Path & $\mathrm{ND}$ & $\begin{array}{l}\text { CR or } \\
\text { MicroPath }\end{array}$ & ND & ND & LC & ND \\
\hline Ozkara et al. [22], 2007 & ClinPath & ClinRadMicro & MicroPath & ND & ND & ND & ND \\
\hline Krenke et al. [23], 2009 & ClinPath & ClinRadMicro & MicroPath & Rad & Clin & LC and SEAG & mean of 9.2 months $^{6}$ \\
\hline \multicolumn{3}{|c|}{$\begin{array}{l}\mathrm{TB}=\text { Tuberculosis; } \mathrm{PE}=\text { pulmonary embolism; Path = pathologic diag- } \\
\text { nosis: demonstration of malignancy in the pleural space by cytology, pleu- } \\
\text { ral biopsy, thoracotomy or autopsy; ND = not defined/described; N/A = not } \\
\text { applicable (no cases were reported); PF = pleural fluid; ClinRadMicro = } \\
\text { clinical and radiographic diagnosis with or without microbiological con- } \\
\text { firmation; MicroPath = microbiological or pathologic diagnosis (positive } \\
\text { tuberculosis culture of pleural fluid, sputum or pleural tissue OR granulo- } \\
\text { mas on pleural biopsy in the absence of other diseases); Rad = radiograph- } \\
\text { ic diagnosis (diagnostic ventilation perfusion scan and/or pulmonary an- } \\
\text { giography); Clin = clinical diagnosis; ClinPath = clinical or pathologic di- } \\
\text { agnosis (diagnostic pleural fluid cytology or pleural biopsy OR an exudate } \\
\text { with a known lung neoplasm in the absence of other diseases); CR = clinical } \\
\text { response (clinical data were suggestive of tuberculosis with positive tuber- } \\
\text { culin skin testing and a typical response to specific anti-tuberculosis ther- } \\
\text { apy); LC = Light's criteria for exudates: pleural fluid/serum protein ratio } \\
>0.5 \text {, pleural fluid/serum lactate dehydrogenase ratio }>0.6 \text {, or pleural fluid }\end{array}$} & \multicolumn{5}{|c|}{$\begin{array}{l}\text { lactate dehydrogenase }>2 / 3 \text { of the normal upper limit for serum lactate de- } \\
\text { hydrogenase; SEAG }=\text { serum effusion albumin gradient } \leq 1.2 \mathrm{~g} / \mathrm{dl} \text {. } \\
{ }^{1} \text { With or without pathologic changes on pleural biopsy commonly seen } \\
\text { in VCD. } \\
{ }^{2} \text { All patients in the tumoral group had primary tumors of the lung or } \\
\text { lung metastasis. } \\
{ }^{3} \text { Criterion for individual diagnosis was not specifically defined. } \\
{ }^{4} \text { Pleural fluid cytology, pleural biopsy and biopsy of other sites were } \\
\text { positive for malignancy in } 42-78 \% \text { of patients classified as malignant pleu- } \\
\text { ral fluid. With characteristic pleural fluid analysis with or without clinical } \\
\text { response to corticosteroid therapy. } \\
{ }^{5} \text { The authors checked whether these patients had previously been treat- } \\
\text { ed with drugs that may have induced EPEs. } \\
{ }^{6} \text { None of these patients had a history of asbestos exposure or treatment } \\
\text { with drugs known to cause EPE. }\end{array}$} \\
\hline
\end{tabular}

and the likelihood of malignancy among EPEs with an area under the receiver operator characteristic curve of 0.71 . The likelihood of malignancy was inversely correlated with the pleural eosinophil counts, as shown in figure 4.

The estimated probability of malignancy for a particular patient with EPE was equal to $y=1 /\left(1+\mathrm{e}^{-\mathrm{z}}\right)$, where $\mathrm{z}=-0.345953-0.043784 \cdot($ pleural eosinophil count), and $\mathrm{e}$ is the mathematical constant and base value of natural logarithms: $p>|z|=0.01$ (95\% CI -0.77 to -0.01 ). The odds of malignancy for every $1 \%$ increase in pleural eosinophil count were 0.96 (95\% CI 0.91-0.99).

Based on the receiver operating characteristic curve, the highest accuracy (maximum sensitivity and specificity) was achieved when a cutoff of pleural fluid eosinophil count was $32 \%$. The probability of malignancy was only 
Table 3. Etiology of EPEs

\begin{tabular}{|c|c|c|c|c|c|c|c|c|c|c|}
\hline Study & Total & $\begin{array}{l}\text { Malig- } \\
\text { nancy }\end{array}$ & $\begin{array}{l}\text { Para- } \\
\text { pneumonic } \\
\text { effusion }\end{array}$ & TB & $\mathrm{PE}$ & $\begin{array}{l}\text { Transu- } \\
\text { date }\end{array}$ & CVD & Other & $\begin{array}{l}\text { Idiopathic } \\
\text { effusion }\end{array}$ & Air/blood \\
\hline Bower [12], 1967 & 21 & $1(5)$ & $1(5)$ & 0 & $2(10)$ & 0 & $1(5)$ & $3(14)$ & $6(29)$ & $7(33)^{1}$ \\
\hline Light et al. [24], 1973 & 8 & $1(13)$ & $2(25)$ & 0 & 0 & 0 & 0 & $2(25)$ & $2(25)$ & $1(13)^{2}$ \\
\hline Kokkola and Valta [13], 1974 & 78 & $6(8)$ & $3(4)$ & $14(18)$ & 0 & 0 & $8(10)$ & $1(1)$ & $44(56)$ & $2(3)$ \\
\hline Hirsch et al. [25], 1979 & 23 & $8(35)$ & $3(13)$ & 0 & 0 & 0 & 0 & 0 & $12(52)$ & 0 \\
\hline Pettersson and Riska [14], 1981 & 26 & $1(4)$ & $3(12)$ & $1(4)$ & 0 & 0 & $8(31)$ & 0 & $12(46)$ & $1(4)$ \\
\hline Mihailescu and Micu [15], 1985 & 11 & $3(27)$ & $1(9)$ & $5(45)$ & 0 & $1(9)$ & 0 & $1(9)$ & 0 & 0 \\
\hline Wysenbeek et al. [16], 1985 & 36 & $7(19)$ & $3(8)$ & 0 & $1(3)$ & $5(14)$ & $1(3)$ & $2(6)$ & $3(8)$ & $14(39)^{3}$ \\
\hline Kuhn et al. [17], 1989 & 22 & $5(23)$ & $1(5)$ & $1(5)$ & $1(5)$ & $3(14)$ & $1(5)$ & 0 & $2(9)$ & $8(36)^{4}$ \\
\hline Lakhotia et al. [18], 1989 & 18 & $1(6)$ & $4(22)$ & 0 & 0 & $1(6)$ & 0 & 0 & $12(67)$ & excluded \\
\hline Rubins and Rubins [6], 1996 & 44 & $10(23)$ & $4(9)$ & 0 & 0 & $9(20)$ & 0 & $3(7)$ & $11(25)$ & $7(16)$ \\
\hline Riantawan et al. [19], 1998 & 31 & $24(77)$ & $2(6)$ & 0 & 0 & 0 & 0 & $3(10)$ & $2(6)$ & excluded \\
\hline Martinez-Garcia et al. [5], 2000 & 45 & $11(24)$ & $15(33)$ & $7(16)$ & $1(2)$ & $4(9)$ & 0 & 0 & $7(16)$ & excluded \\
\hline Kalomenidis and Light [1], 2003 & 53 & $15(28)$ & $8(15)$ & 0 & 0 & $9(17)$ & 0 & $4(8)$ & $17(32)$ & 0 \\
\hline Matthai and Kini [20], 2003 & 26 & $4(15)$ & $7(27)$ & $5(19)$ & 0 & $3(12)$ & 0 & $6(23)$ & $1(4)$ & 0 \\
\hline \multicolumn{11}{|l|}{ Reechaipichitkul and } \\
\hline Chuesakoolvanich [21], 2003 & 50 & $12(24)$ & $3(6)$ & $3(6)$ & 0 & 0 & 0 & $2(4)$ & $5(10)$ & $25(50)^{5}$ \\
\hline Ozkara et al. [22], 2007 & 60 & $22(37)$ & $3(5)$ & $6(10)$ & $3(5)$ & $2(3)$ & $2(3)$ & $3(5)$ & $18(30)$ & $1(2)$ \\
\hline Krenke et al. [23], 2009 & 135 & $47(35)$ & $23(17)$ & $3(2)$ & $3(2)$ & $7(5)$ & $2(1)$ & $10(7)$ & $19(14)$ & $21(16)$ \\
\hline Total & 687 & $178(26)$ & $86(13)$ & $45(7)$ & $11(2)$ & $44(6)$ & $23(3)$ & $40(6)$ & $173(25)$ & $63(13)$ \\
\hline
\end{tabular}

Data are presented as n (\%). TB = Tuberculosis; PE = pulmonary embolism. ${ }^{1}$ Three cases $(2$ malignancy and 1 pulmonary embolism) were reclassified as air/blood since EPE was found only on repeated thoracentesis. ${ }^{2}$ One tuberculosis case was reclassified as air/blood since EPE was found only on repeated thoracentesis. ${ }^{3}$ Five malignancy cases were reclassified as air/blood since EPE was found only on repeated thoracentesis. ${ }^{4}$ Eight cases (5 malig- nancy, 2 pulmonary embolism and 1 parapneumonic) were reclassified as air/blood since EPE was found only on repeated thoracentesis or associated with chest trauma or pneumothorax. ${ }^{5}$ Twenty-four cases (11 malignancy, 2 parapneumonic, 2 tuberculosis, 1 transudate, 2 other and 6 idiopathic) were reclassified as air/blood since EPE was found only on repeated thoracentesis.

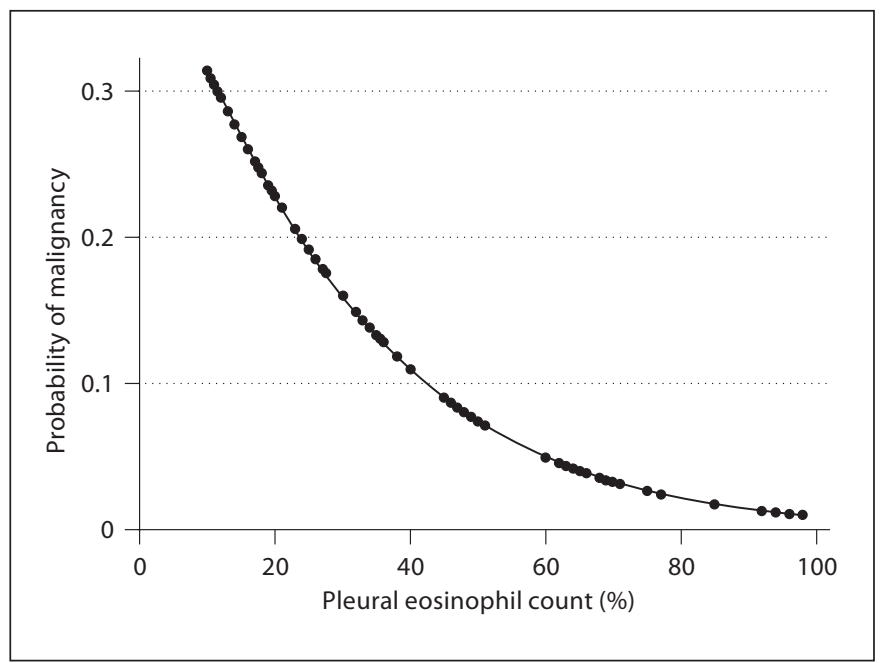

Fig. 4. Correlation between the probability of malignancy and pleural fluid eosinophil counts in 144 cases with EPE.

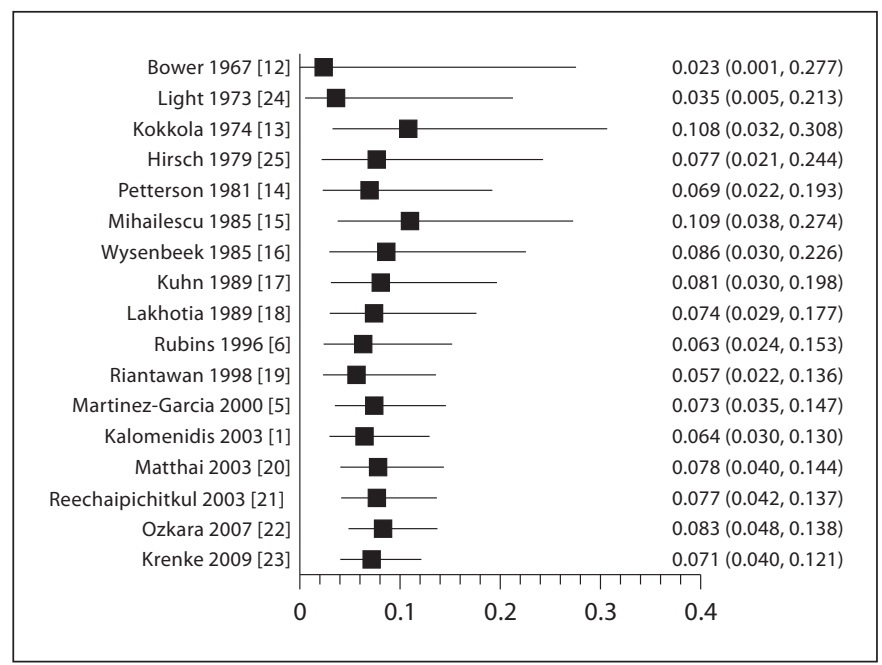

Fig. 5. Cumulative prevalence of tuberculosis in cases with EPEs. Each later estimate is a pooled estimate of all previous studies. Data are ORs, with confidence limits in parentheses. 
Table 4. Comparison of disease spectrum between EPEs and non-EPEs

\begin{tabular}{|c|c|c|c|c|c|c|c|c|}
\hline Study & Total & Malignancy & $\begin{array}{l}\text { Parapneumonic } \\
\text { effusion }\end{array}$ & TB & PE & CVD & Other & $\begin{array}{l}\text { Idiopathic } \\
\text { effusion }\end{array}$ \\
\hline Light et al. [24], 1973 & $125 / 7$ & $42(34) / 1(14)$ & $24(19) / 2(29)$ & $13(10) / 0(0)$ & $5(4) / 0(0)$ & $2(2) / 0(0)$ & $8(6) / 2(29)$ & $31(25) / 2(29)$ \\
\hline Hirsch et al. [25], 1979 & $246 / 23$ & $109(44) / 8(35)$ & $35(14) / 3(13)$ & $52(21) / 0(0)$ & $0(0) / 0(0)$ & $0(0) / 0(0)$ & $0(0) / 0(0)$ & $50(20) / 12(52)$ \\
\hline Pettersson and Riska [14], 1981 & $89 / 25$ & $23(26) / 1(4)$ & $8(9) / 3(12)$ & $30(34) / 1(4)$ & $0(0) / 0(0)$ & $11(12) / 8(32)$ & $3(3) / 0(0)$ & $14(16) / 12(48)$ \\
\hline Mihailescu and Micu [15], 1985 & $126 / 10$ & $73(58) / 3(30)$ & $7(6) / 1(10)$ & $36(29) / 5(50)$ & $0(0) / 0(0)$ & $0(0) / 0(0)$ & $10(8) / 1(10)$ & $0(0) / 0(0)$ \\
\hline Kuhn et al. [17], 1989 & $141 / 11$ & $80(57) / 5(45)$ & $30(21) / 1(9)$ & $6(4) / 1(9)$ & $6(4) / 1(9)$ & $1(1) / 1(9)$ & $0(0) / 0(0)$ & $18(13) / 2(18)$ \\
\hline Lakhotia et al. [18], 1989 & $135 / 17$ & $31(23) / 1(6)$ & $16(12) / 4(24)$ & $68(50) / 0(0)$ & $0(0) / 0(0)$ & $2(1) / 0(0)$ & $2(1) / 0(0)$ & $16(12) / 12(71)$ \\
\hline Riantawan et al. [19], 1998 & $363 / 31$ & $135(37) / 24(77)$ & $48(13) / 2(6)$ & $155(43) / 0(0)$ & $2(0.6) / 0(0)$ & $1(0.3) / 0(0)$ & $6(2) / 3(10)$ & $16(4) / 2(6)$ \\
\hline Martinez-Garcia et al. [5], 2000 & $254 / 41$ & $84(33) / 11(27)$ & $58(23) / 15(37)$ & $65(26) / 7(17)$ & $3(1) / 1(2)$ & $4(2) / 0(0)$ & $12(5) / 0(0)$ & $28(11) / 7(17)$ \\
\hline
\end{tabular}

Data are presented as $\mathrm{n}(\%)$ of non-EPE/EPE. Transudates and cases resulting from pleural air/blood were excluded. TB = Tuberculosis; PE = pulmonary embolism.

$7 \%$ when a pleural fluid eosinophil count was $\geq 32 \%$. Using this cutoff, the sensitivity, specificity and positive and negative predictive values were 77, 56, 24 and $93 \%$, respectively.

\section{Tuberculosis}

The cumulative prevalence of tuberculosis in EPEs has been relatively stable for the last 4 decades and stayed at around 7\% (fig. 5). The odds of tuberculosis in EPEs, as compared with non-EPEs, was 0.29 (95\% CI 0.07-1.09; $\mathrm{p}=0.07$ ) (fig. 6). The OR became statistically significant when the study by Mihailescu and Micu [15] (OR 0.20, $95 \%$ CI $0.06-0.70 ; \mathrm{p}<0.05$ ) or Kuhn et al. [17] (OR 0.22, $95 \%$ CI $0.06-0.84 ; \mathrm{p}<0.05)$ was excluded from the analysis. The logistic regression analysis failed to show a significant correlation between the pleural fluid eosinophil counts and the likelihood of tuberculosis among EPEs (OR 1.01, 95\% CI 0.99-1.03; $\mathrm{p}=0.42$ ).

\section{Parapneumonic Effusion and Pulmonary Embolism}

The prevalence of parapneumonic effusion or pulmonary embolism was not statistically different in EPEs as compared with non-EPEs (OR 1.27, fixed-effects model, 95\% CI 0.83-1.95, $\mathrm{p}=0.32$; OR 2.02, fixed-effects model, $95 \%$ CI $0.57-7.22, \mathrm{p}=0.49$, respectively). The result was unchanged when the included studies were removed individually or analyzed using a random-effects model, relative risk and risk difference. There was no significant association between the pleural fluid eosinophil counts and the likelihood of parapneumonic effusion or pulmonary embolism ( $\mathrm{p}=0.78$ and 0.20 , respectively).

\section{Collagen Vascular Disease}

Six studies reported the prevalence of CVD-associated pleural effusions in non-EPEs and EPEs [5, 14, 17-19, 24].
The prevalence of CVD-associated pleural effusions was significantly higher in EPEs compared with non-EPEs (OR 2.84, fixed-effects model, 95\% CI 1.28-6.31; $\mathrm{p}=0.02$ ) (fig. 7). The result was unchanged when the included studies were analyzed using a random-effects model, relative risk and risk difference. However, the OR became statistically non-significant when the study by Pettersson and Riska [14] was excluded from the analysis (OR $2.18,95 \%$ CI $0.61-7.76 ; \mathrm{p}=0.41$ ). There was no significant association between the pleural fluid eosinophil counts and the likelihood of CVD-associated pleural effusion $(p=0.06)$.

\section{Idiopathic Pleural Effusion}

The duration of follow-up to confirm the diagnosis of idiopathic effusions varied. Five studies described the duration of follow-up, but the rest of the studies did not (table 2). The prevalence of idiopathic pleural effusions was significantly lower in the studies that reported certain duration of follow-up (23 vs. $32 \%$; $p=0.03$ ).

The prevalence of idiopathic pleural effusions was significantly higher in EPEs than in non-EPEs (OR 3.20, 95\% CI 1.60-6.39; $\mathrm{p}=0.001$ ) (fig. 8). The result was unchanged when the included studies were removed individually or analyzed using a fixed-effects model, relative risk and risk difference. There was no significant association between the pleural fluid eosinophil counts and the likelihood of idiopathic pleural effusion $(\mathrm{p}=0.96)$.

\section{Other Causes}

Other causes of EPEs were as follows: gastrointestinal diseases in 12 (pancreatic diseases, subdiaphragmatic abscess/inflammation), cardiovascular diseases in 5 (myocardial infarction, postcardiac injury syndrome, aortic aneurysm), eosinophilic lung diseases in 5, parasitic in- 


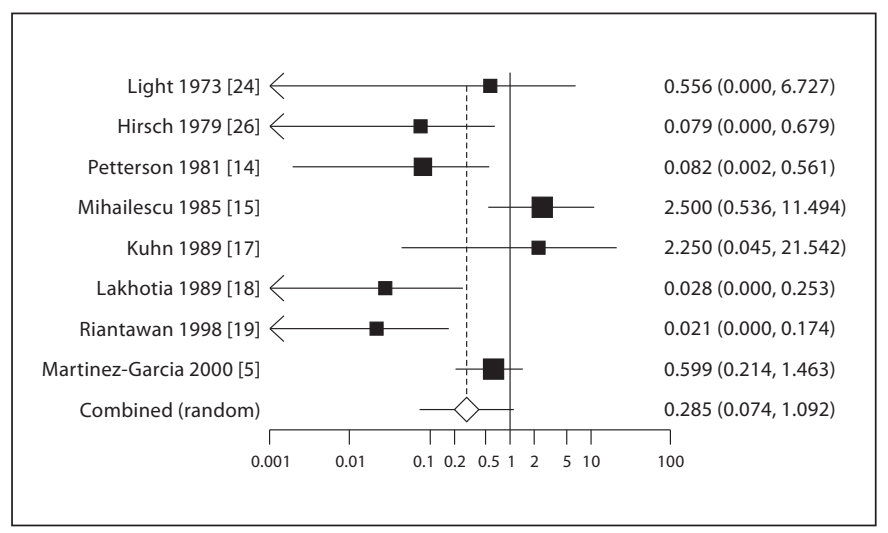

Fig. 6. OR meta-analysis plot (random-effects model). Pooled OR for tuberculosis in EPEs as compared with non-EPEs. Test for heterogeneity: $\chi^{2}=3.35$ (d.f. $=1$ ); $\mathrm{I}^{2}=73.9 \%$. Data are ORs, with confidence limits in parentheses.

fections in 3 (strongyloides, paragonimiasis, hydatid cyst), occupational lung diseases in 2 (benign asbestos effusion, byssinosis), 'serositis' in 2, atelectasis in 2, 'hypersensitivity state' in 1 , viral pleuritis in 1, actinomycosis in 1 , radiation therapy in 1 , and Gorham's disease in 1 case. The etiology was not specified in 4 cases which were classified as 'other' in 1 study [1]. The prevalence of pleural effusions resulting from other causes was not statistically different in EPEs as compared with non-EPEs (OR 1.56, fixed-effects model, 95\% CI 0.71-3.47; $\mathrm{p}=0.37$ ). The result was unchanged when the included studies were removed individually or analyzed using a random-effects model, relative risk and risk difference.

\section{Discussion}

Our systematic review of the medical literature identified a total of 687 cases of EPE. The most common cause of EPE was malignancy (26\%) followed by idiopathic (25\%) and parapneumonic (13\%) effusions, pleural air/ blood (13\%), tuberculosis (7\%), transudate (7\%), other (6\%) and CVD (3\%).

The cumulative prevalence of malignancy among EPEs has gradually increased from 7 to $25 \%$ over the last 4 decades, while that of tuberculosis has been relatively stable and stayed at around 7\% (fig. 2, 5). The likelihood of malignancy or tuberculosis was somehow lower in EPEs than in non-EPEs, but the difference was not statistically significant. We found that the likelihood of malignancy was inversely correlated with the pleural eosino-

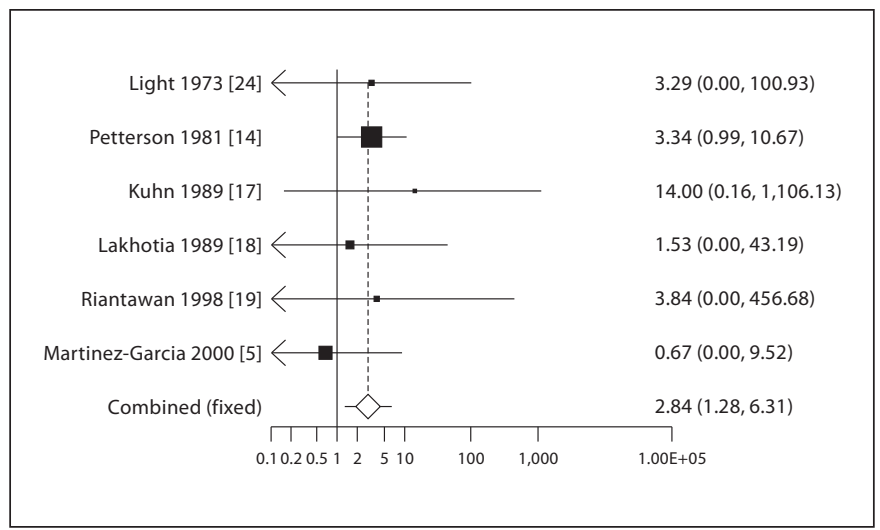

Fig. 7. OR meta-analysis plot (fixed-effects model). Pooled OR for CVD-associated pleural effusion in EPEs as compared with nonEPEs. Test for heterogeneity: $\chi^{2}=5.61 ; I^{2}=0 \%$. Data are ORs, with confidence limits in parentheses.

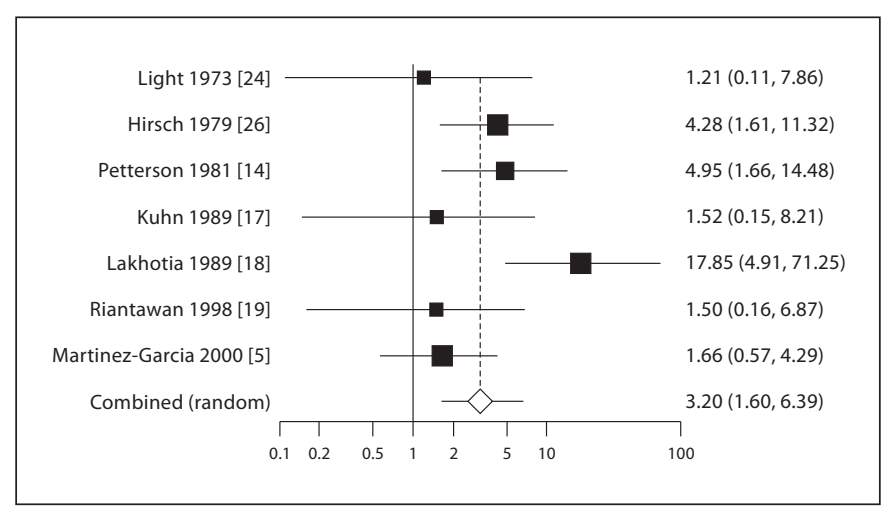

Fig. 8. OR meta-analysis plot (random-effects model). Pooled OR for identical pleural effusion in EPEs as compared with non-EPEs. Test for heterogeneity: $\chi^{2}=10.8($ d.f. $=1) ; \mathrm{I}^{2}=58.7 \%$. Data are ORs, with confidence limits in parentheses.

phil counts (fig. 4). Such correlation was not found in tuberculosis.

The above findings could explain the difference in opinion on the diagnostic significance of EPE in the medical literature. Adelman et al. [4] reported that the prevalence of malignancy among EPEs was $4.9 \%$ and concluded that the presence of pleural fluid eosinophilia considerably reduced the probability of malignancy. However, Kuhn et al. [17] reported a much higher prevalence of malignancy (40\%) among EPEs which is most likely due to the different population they studied. In addition, 2 recent studies demonstrated that the prevalence of malig- 
nancy was as frequent in EPEs as in non-EPEs - 20.5 versus $20.1 \%$ in the study by Rubins and Rubins [6] and 24.4 versus $26.8 \%$ in the study by Martinez-Garcia et al. [5].

EPEs appeared to be a very weak negative predictor of malignancy when the conventional cutoff of $10 \%$ was used (OR 0.63, 95\% CI 0.28-1.47). In addition, we found that the higher a pleural fluid eosinophil count was, the lower the likelihood of malignancy (fig. 4). The probability of malignancy was only $7 \%$ when a pleural fluid eosinophil count was $>32 \%$ in our analysis, which is in accordance with a study by Martensson et al. [30] who concluded that more than $30 \%$ eosinophils in the pleural fluid had the strongest negative predictability towards malignancy.

The likelihood of malignancy in a pleural effusion is affected by various factors, and the presence of pleural fluid eosinophilia by no means excludes malignancy. The clinical predictors for malignant pleural effusions include older age, a symptomatic period $>1$ month, absence of fever, blood-tinged pleural effusion, large or massive pleural effusion, and chest CT scan findings suggestive of malignancy [31-33]. Thus, it is not surprising that one of the patients with malignant pleural effusion had a pleural eosinophil count of 70\% [27].

Our study has several limitations. First, the baseline characteristics between EPEs and non-EPEs are not matched and the presence of confounding factors cannot be excluded. We attempted to adjust for known confounding factors, but it was impossible because of the lack of information. The clinical heterogeneity, such as different types and degrees of confounding factors in each study, could explain the weak robustness of effect size in several analyses. A large multicenter prospective study is needed to better characterize the diagnostic significance of EPEs. However, the pooled comparison of disease spectrum between EPEs and non-EPEs may provide the most generalizable information on the diagnostic significance of EPEs in the absence of such study.

Second, the diagnostic criteria were somehow different from study to study. The prevalence of malignancy was significantly lower in studies that required a pathologic confirmation and the prevalence of idiopathic pleural effusions was significantly lower in studies that required certain duration of follow-up. The prevalence of malignancy among EPEs was likely underestimated and that of idiopathic effusions was likely overestimated in our analysis. As in exudative pleural effusions, a certain duration of follow-up would be strongly recommended in EPEs in order not to overlook malignancy when an initial work-up is unrevealing.
Third, we tried to limit the cases of EPE only with the first thoracentesis, but it was not possible in some studies $[1,13,15,22]$. This factor may have affected the results on the prevalence and diagnostic significance of EPEs. However, recent studies suggested that the prevalence of EPEs with a repeated thoracentesis was similar to that of EPEs with the first thoracentesis $[5,23]$.

Fourth, the prevalence of idiopathic pleural effusion may be overestimated because there were no cases of drug-induced EPE reported among the included studies and only 1 study indicated that the possibility of druginduced EPE was investigated [5]. At least 10 drugs are known to be associated with EPEs [1], but the prevalence of the drug-induced EPEs is poorly studied. The presence of peripheral eosinophilia may suggest parasitic or medication-induced EPE, but it is not helpful to delineate the etiology of EPE since it can be found in patients with malignancy including Hodgkin's disease, pulmonary embolism, trauma and infections $[1,16,26]$. In addition, there is no correlation between the number of eosinophils in the peripheral blood and the pleural fluid [6].

It was once believed that EPEs denoted a favorable prognosis, based on their association with benign diseases such as air or blood in the pleural space, benign asbestos-related pleural effusion, parasitic infection and drug effect [34]. The prevalence of the above-mentioned diagnoses was actually very low in our pooled analysis except for air or blood in the pleural space. It is possible that a significant proportion of the idiopathic pleural effusions were actually due to medications, asbestos or other unrecognized benign diseases.

Despite the limitations described above, our analysis gives an insight and explanation for the difference of opinions in the medical literature on this topic. The disease spectrum of EPEs has changed since 1960, and malignancy should no longer be considered uncommon among EPEs. Some medical textbooks still describe that EPEs militate greatly against malignancy or tuberculosis $[35,36]$. The readers are warned not to be misled by information from the remote past.

\section{Financial Disclosure and Conflicts of Interest}

None of the authors received financial support. 


\section{Appendix}

Quality of Included Studies

\begin{tabular}{|c|c|c|c|c|c|c|c|c|c|c|c|c|c|c|c|c|c|}
\hline & Bower & Light & Kokkola & Hirsch & $\begin{array}{l}\text { Petters- } \\
\text { son }\end{array}$ & $\begin{array}{l}\text { Mihai- } \\
\text { lescu }\end{array}$ & $\begin{array}{l}\text { Wysen- } \\
\text { Beek }\end{array}$ & Kuhn & Lakhotia & Rubins & $\begin{array}{l}\text { Rianta- } \\
\text { wan }\end{array}$ & $\begin{array}{l}\text { Martinez- } \\
\text { Garcia }\end{array}$ & $\begin{array}{l}\text { Kalo- } \\
\text { menidis }\end{array}$ & Matthai & $\begin{array}{l}\text { Reechai- } \\
\text { Pichitkul }\end{array}$ & Ozkara & Krenke \\
\hline 1. & $\mathrm{Y}$ & $\mathrm{Y}$ & $\mathrm{Y}$ & $\mathrm{Y}$ & $\mathrm{Y}$ & $\mathrm{Y}$ & $\mathrm{Y}$ & $\mathrm{Y}$ & $\mathrm{Y}$ & $\mathrm{Y}$ & $\mathrm{Y}$ & $\mathrm{Y}$ & $\mathrm{N}$ & $\mathrm{Y}$ & $\mathrm{Y}$ & $\mathrm{Y}$ & $\mathrm{Y}$ \\
\hline 2. & $\mathrm{Y}$ & $\mathrm{Y}$ & $\mathrm{Y}$ & Y & $\mathrm{Y}$ & Y & $\mathrm{Y}$ & $\mathrm{Y}$ & Y & $\mathrm{Y}$ & $\mathrm{Y}$ & $\mathrm{Y}$ & $\mathrm{Y}$ & $\mathrm{Y}$ & $\mathrm{Y}$ & $\mathrm{Y}$ & Y \\
\hline 3. & Y & $\mathrm{Y}$ & $\mathrm{Y}$ & Y & $\mathrm{Y}$ & $\mathrm{Y}$ & $\mathrm{Y}$ & $\mathrm{Y}$ & Y & $\mathrm{Y}$ & $\mathrm{Y}$ & $\mathrm{Y}$ & $\mathrm{N}$ & $\mathrm{Y}$ & $\mathrm{Y}$ & $\mathrm{Y}$ & Y \\
\hline 4. & $\mathrm{~N}$ & $\mathrm{Y}$ & $\mathrm{Y}$ & Y & $\mathrm{Y}$ & $\mathrm{N}$ & $\mathrm{Y}$ & $\mathrm{Y}$ & $\mathrm{Y}$ & $\mathrm{Y}$ & Y & $\mathrm{Y}$ & $\mathrm{N}$ & $\mathrm{Y}$ & $\mathrm{Y}$ & $\mathrm{Y}$ & $\mathrm{Y}$ \\
\hline 5. & $\mathrm{Y}$ & $\mathrm{Y}$ & $\mathrm{N}$ & $\mathrm{Y}$ & $\mathrm{Y}$ & $\mathrm{N}$ & $\mathrm{Y}$ & $\mathrm{Y}$ & $\mathrm{N}$ & $\mathrm{Y}$ & $\mathrm{Y}$ & $\mathrm{Y}$ & $\mathrm{N}$ & $\mathrm{Y}$ & $\mathrm{Y}$ & $\mathrm{Y}$ & $\mathrm{Y}$ \\
\hline 6. & $\mathrm{~N}$ & $\mathrm{Y}$ & $\mathrm{Y}$ & $\mathrm{Y}$ & $\mathrm{Y}$ & $\mathrm{N}$ & $\mathrm{Y}$ & $\mathrm{Y}$ & $\mathrm{Y}$ & $\mathrm{Y}$ & $\mathrm{Y}$ & $\mathrm{Y}$ & $\mathrm{N}$ & $\mathrm{Y}$ & $\mathrm{Y}$ & $\mathrm{Y}$ & $\mathrm{Y}$ \\
\hline 7. & $\mathrm{~N}$ & $\mathrm{~N}$ & $\mathrm{~N}$ & $\mathrm{~N}$ & $\mathrm{~N}$ & $\mathrm{~N}$ & $\mathrm{~N}$ & Y & $\mathrm{N}$ & $\mathrm{Y}$ & $\mathrm{N}$ & $\mathrm{N}$ & $\mathrm{N}$ & $\mathrm{N}$ & Y & $\mathrm{N}$ & $\mathrm{N}$ \\
\hline 8. & $\mathrm{~N}$ & $\mathrm{Y}$ & $\mathrm{N}$ & $\mathrm{N}$ & $\mathrm{N}$ & $\mathrm{N}$ & Y & Y & $\mathrm{Y}$ & $\mathrm{Y}$ & $\mathrm{Y}$ & $\mathrm{Y}$ & $\mathrm{N}$ & Y & Y & $\mathrm{Y}$ & $\mathrm{Y}$ \\
\hline 9. & $\mathrm{~N}$ & $\mathrm{~N}$ & $\mathrm{~N}$ & $\mathrm{~N}$ & $\mathrm{~N}$ & $\mathrm{~N}$ & $\mathrm{~N}$ & $\mathrm{Y}$ & $\mathrm{N}$ & $\mathrm{Y}$ & $\mathrm{N}$ & $\mathrm{N}$ & $\mathrm{N}$ & $\mathrm{N}$ & $\mathrm{Y}$ & $\mathrm{N}$ & $\mathrm{N}$ \\
\hline 10. & $\mathrm{~N}$ & $\mathrm{~N}$ & $\mathrm{~N}$ & $\mathrm{Y}$ & $\mathrm{N}$ & $\mathrm{N}$ & $\mathrm{N}$ & $\mathrm{N}$ & $\mathrm{N}$ & $\mathrm{Y}$ & $\mathrm{N}$ & $\mathrm{N}$ & $\mathrm{N}$ & $\mathrm{N}$ & $\mathrm{N}$ & $\mathrm{N}$ & $\mathrm{N}$ \\
\hline 11. & $\mathrm{Y}$ & $\mathrm{Y}$ & $\mathrm{Y}$ & $\mathrm{Y}$ & $\mathrm{Y}$ & $\mathrm{Y}$ & $\mathrm{Y}$ & $\mathrm{Y}$ & $\mathrm{Y}$ & $\mathrm{Y}$ & $\mathrm{Y}$ & $\mathrm{Y}$ & $\mathrm{Y}$ & $\mathrm{Y}$ & $\mathrm{Y}$ & $\mathrm{Y}$ & $\mathrm{Y}$ \\
\hline 12. & $\mathrm{~N}$ & $\mathrm{~N}$ & $\mathrm{~N}$ & $\mathrm{~N}$ & $\mathrm{~N}$ & $\mathrm{~N}$ & $\mathrm{~N}$ & $\mathrm{Y}$ & $\mathrm{N}$ & $\mathrm{Y}$ & $\mathrm{N}$ & $\mathrm{N}$ & $\mathrm{N}$ & $\mathrm{N}$ & $\mathrm{N}$ & $\mathrm{N}$ & $\mathrm{N}$ \\
\hline 13. & $\mathrm{Y}$ & $\mathrm{Y}$ & $\mathrm{Y}$ & $\mathrm{Y}$ & $\mathrm{Y}$ & $\mathrm{Y}$ & $\mathrm{Y}$ & $\mathrm{Y}$ & $\mathrm{Y}$ & $\mathrm{Y}$ & $\mathrm{Y}$ & $\mathrm{Y}$ & $\mathrm{Y}$ & $\mathrm{Y}$ & $\mathrm{Y}$ & $\mathrm{Y}$ & $\mathrm{Y}$ \\
\hline 14. & $\mathrm{Y}$ & $\mathrm{N}$ & $\mathrm{Y}$ & $\mathrm{Y}$ & $\mathrm{Y}$ & $\mathrm{N}$ & $\mathrm{Y}$ & $\mathrm{N}$ & $\mathrm{N}$ & $\mathrm{Y}$ & $\mathrm{Y}$ & $\mathrm{Y}$ & $\mathrm{N}$ & $\mathrm{Y}$ & $\mathrm{Y}$ & $\mathrm{Y}$ & $\mathrm{Y}$ \\
\hline 15. & $\mathrm{Y}$ & $\mathrm{Y}$ & $\mathrm{Y}$ & $\mathrm{Y}$ & $\mathrm{Y}$ & $\mathrm{Y}$ & $\mathrm{Y}$ & $\mathrm{Y}$ & $\mathrm{Y}$ & $\mathrm{Y}$ & $\mathrm{Y}$ & $\mathrm{Y}$ & $\mathrm{Y}$ & $\mathrm{Y}$ & $\mathrm{Y}$ & $\mathrm{Y}$ & $\mathrm{Y}$ \\
\hline 16. & $\mathrm{Y}$ & $\mathrm{Y}$ & $\mathrm{Y}$ & $\mathrm{Y}$ & $\mathrm{Y}$ & $\mathrm{Y}$ & $\mathrm{Y}$ & $\mathrm{Y}$ & $\mathrm{Y}$ & $\mathrm{Y}$ & $\mathrm{Y}$ & $\mathrm{Y}$ & $\mathrm{Y}$ & $\mathrm{Y}$ & $\mathrm{Y}$ & $\mathrm{Y}$ & $\mathrm{Y}$ \\
\hline 17. & $\mathrm{~N}$ & $\mathrm{Y}$ & $\mathrm{Y}$ & $\mathrm{Y}$ & $\mathrm{Y}$ & $\mathrm{N}$ & $\mathrm{Y}$ & $\mathrm{Y}$ & $\mathrm{Y}$ & $\mathrm{Y}$ & $\mathrm{Y}$ & $\mathrm{Y}$ & $\mathrm{N}$ & $\mathrm{N}$ & $\mathrm{Y}$ & $\mathrm{N}$ & $\mathrm{Y}$ \\
\hline 18. & $\mathrm{Y}$ & $\mathrm{N}$ & $\mathrm{N}$ & $\mathrm{N}$ & $\mathrm{N}$ & $\mathrm{Y}$ & $\mathrm{N}$ & $\mathrm{Y}$ & $\mathrm{N}$ & $\mathrm{Y}$ & $\mathrm{Y}$ & $\mathrm{Y}$ & $\mathrm{N}$ & $\mathrm{N}$ & $\mathrm{N}$ & $\mathrm{N}$ & $\mathrm{N}$ \\
\hline 19. & $\mathrm{~N}$ & $\mathrm{~N}$ & $\mathrm{~N}$ & $\mathrm{~N}$ & $\mathrm{~N}$ & $\mathrm{~N}$ & $\mathrm{~N}$ & $\mathrm{~N}$ & $\mathrm{~N}$ & $\mathrm{~N}$ & $\mathrm{~N}$ & $\mathrm{~N}$ & $\mathrm{~N}$ & $\mathrm{~N}$ & $\mathrm{~N}$ & $\mathrm{~N}$ & $\mathrm{~N}$ \\
\hline 20. & $\mathrm{~N}$ & $\mathrm{~N}$ & $\mathrm{~N}$ & $\mathrm{~N}$ & $\mathrm{~N}$ & $\mathrm{~N}$ & $\mathrm{~N}$ & $\mathrm{Y}$ & $\mathrm{N}$ & $\mathrm{N}$ & $\mathrm{N}$ & $\mathrm{N}$ & $\mathrm{N}$ & $\mathrm{N}$ & $\mathrm{N}$ & $\mathrm{N}$ & $\mathrm{N}$ \\
\hline 21. & $\mathrm{~N}$ & $\mathrm{~N}$ & $\mathrm{~N}$ & $\mathrm{~N}$ & $\mathrm{~N}$ & $\mathrm{~N}$ & $\mathrm{~N}$ & $\mathrm{~N}$ & $\mathrm{~N}$ & $\mathrm{~N}$ & $\mathrm{~N}$ & $\mathrm{~N}$ & $\mathrm{~N}$ & $\mathrm{~N}$ & $\mathrm{~N}$ & $\mathrm{~N}$ & $\mathrm{~N}$ \\
\hline 22. & $\mathrm{~N}$ & $\mathrm{Y}$ & $\mathrm{N}$ & $\mathrm{N}$ & $\mathrm{Y}$ & $\mathrm{N}$ & $\mathrm{N}$ & $\mathrm{N}$ & $\mathrm{N}$ & $\mathrm{N}$ & $\mathrm{N}$ & $\mathrm{N}$ & $\mathrm{N}$ & $\mathrm{N}$ & $\mathrm{N}$ & $\mathrm{N}$ & $\mathrm{N}$ \\
\hline Total score & 10 & 13 & 11 & 13 & 13 & 8 & 13 & 17 & 11 & 18 & 14 & 14 & 5 & 12 & 15 & 12 & 13 \\
\hline
\end{tabular}

Items that should be included.

1. (a) Indicate the study's design with a commonly used term in the title or the abstract. (b) Provide in the abstract an informative and balanced summary of what was done and what was found.

2. Explain the scientific background and rationale for the investigation being reported.

3. State specific objectives, including any prespecified hypotheses.

4. Present key elements of the study design early in the paper.

5. Describe the setting, locations and relevant dates, including periods of recruitment, exposure, follow-up and data collection.

6. (a) Cohort study: give the eligibility criteria, and the sources and methods of the selection of participants. Describe methods of follow-up. Case-control study: give the eligibility criteria, and the sources and methods of the case ascertainment and control selection. Give the rationale for the choice of cases and controls. Cross-sectional study: give the eligibility criteria, and the sources and methods of the selection of participants. (b) Cohort study: for matched studies, give matching criteria and number of exposed and unexposed. Case-control study: for matched studies, give matching criteria and the number of controls per case.

7. Clearly define all outcomes, exposures, predictors, potential confounders and effect modifiers. Give diagnostic criteria, if applicable.

8. For each variable of interest, give sources of data and details of methods of assessment (measurement). Describe comparability of assessment methods if there is more than one group.

9. Describe any efforts to address potential sources of bias.

10. Explain how the study size was arrived at.

11. Explain how quantitative variables were handled in the analyses. If applicable, describe which groupings were chosen and why.

12. (a) Describe all statistical methods, including those used to control for confounding. (b) Describe any methods used to examine subgroups and interactions. (c) Explain how missing data were addressed. (d) Cohort study: if applicable, explain how loss to follow-up was addressed. Case-control study: if applicable, explain how matching of cases and controls was addressed. Cross-sectional study: if applicable, describe analytical methods taking account of sampling strategy. (e) Describe any sensitivity analyses.

13. (a) Report numbers of individuals at each stage of study - e.g., numbers of potentially eligible, examined for eligibility, confirmed eligible, included in the study, completing follow-up, and analyzed. (b) Give reasons for non-participation at each stage. (c) Consider use of a flow diagram.

14. (a) Give characteristics of study participants (e.g., demographic, clinical, social) and information on exposures and potential confounders. (b) Indicate number of participants with missing data for each variable of interest. (c) Cohort study: summarize follow-up time (e.g., average and total amount).

15. Cohort study: report numbers of outcome events or summary measures over time. Case-control study: report numbers in each exposure category, or summary measures of exposure. Cross-sectional study: report numbers of outcome events or summary measures.

16. (a) Give unadjusted estimates and, if applicable, confounder-adjusted estimates and their precision (e.g., 95\% CI). Make clear which confounders were adjusted for and why they were included. (b) Report category boundaries when continuous variables were categorized. (c) If relevant, consider translating estimates of relative risk into absolute risk for a meaningful time period.

17. Report other analyses done - e.g., analyses of subgroups and interactions, and sensitivity analyses.

18. Summarize key results with reference to study objectives

19. Discuss limitations of the study, taking into account sources of potential bias or imprecision. Discuss both direction and magnitude of any potential bias.

20 . Give a cautious overall interpretation of results considering objectives, limitations, multiplicity of analyses, results from similar studies and other relevant evidence.

21 . Discuss the generalizability (external validity) of the study results.

22. Give the source of funding and the role of the funders for the present study and, if applicable, for the original study on which the present article is based. 


\section{References}

1 Kalomenidis I, Light RW: Eosinophilic pleural effusions. Curr Opin Pulm Med 2003;9: 254-260.

2 Mohamed KH, Abdelhamid AI, Lee YC, Lane $\mathrm{KB}$, Conner B, Hawthorne M, et al: Pleural fluid levels of interleukin-5 and eosinophils are closely correlated. Chest 2002; 122:576-580

-3 Kalomenidis I, Light RW: Pathogenesis of the eosinophilic pleural effusions. Curr Opin Pulm Med 2004;10:289-293.

$\checkmark 4$ Adelman M, Albelda SM, Gottlieb J, Haponik EF: Diagnostic utility of pleural fluid eosinophilia. Am J Med 1984;77:915-920.

$\checkmark 5$ Martinez-Garcia MA, Cases-Viedma E, Cordero-Rodriguez PJ, Hidalgo-Ramirez M, Perpina-Tordera M, Sanchis-Moret F, et al: Diagnostic utility of eosinophils in the pleural fluid. Eur Respir J 2000;15:166-169.

6 Rubins JB, Rubins HB: Etiology and prognostic significance of eosinophilic pleural effusions. A prospective study. Chest 1996;110: 1271-1274.

-7 Vandenbroucke JP, von Elm E, Altman DG, Gotzsche PC, Mulrow CD, Pocock SJ, et al: Strengthening the Reporting of Observational Studies in Epidemiology (STROBE): explanation and elaboration. PLoS Med 2007;4:e297.

$\checkmark 8$ Lau J, Schmid CH, Chalmers TC: Cumulative meta-analysis of clinical trials builds evidence for exemplary medical care. J Clin Epidemiol 1995;48:45-57, discussion 59-60.

-9 Higgins JP, Thompson SG, Deeks JJ, Altman DG: Measuring inconsistency in meta-analyses. BMJ 2003;327:557-560

$\checkmark 10$ Normand SL: Meta-analysis: formulating, evaluating, combining, and reporting. Stat Med 1999;18:321-359.

11 Egger M, Smith GD, Phillips AN: Meta-analysis: principles and procedures. BMJ 1997; 315:1533-1537.
12 Bower G: Eosinophilic pleural effusion. A condition with multiple causes. Am Rev Respir Dis 1967;95:746-751.

13 Kokkola K, Valta R: Aetiology and findings in eosinophilic pleural effusion. Scand J Respir Dis Suppl 1974;89:159-165.

14 Pettersson T, Riska H: Diagnostic value of total and differential leukocyte counts in pleural effusions. Acta Med Scand 1981;210:129135.

$\checkmark 15$ Mihailescu E, Micu D: Eosinophilia in the pleural and peritoneal effusions. Med Interne 1985;23:191-194.

-16 Wysenbeek AJ, Lahav M, Aelion JA, Kaufmann L: Eosinophilic pleural effusion: a review of 36 cases. Respiration 1985;48:7376.

17 Kuhn M, Fitting JW, Leuenberger P: Probability of malignancy in pleural fluid eosinophilia. Chest 1989;96:992-994.

18 Lakhotia M, Mehta SR, Mathur D, Baid CS, Varma AR: Diagnostic significance of pleural fluid eosinophilia during initial thoracocentesis. Indian J Chest Dis Allied Sci 1989; 31:259-264.

19 Riantawan P, Bangpattanasiri K, Chaowalit P, Sangsayan P: Etiology and clinical implications of eosinophilic pleural effusions. Southeast Asian J Trop Med Public Health 1998:29:655-659.

20 Matthai SM, Kini U: Diagnostic value of eosinophils in pleural effusion: a prospective study of 26 cases. Diagn Cytopathol 2003;28: 96-99.

21 Reechaipichitkul W, Chuesakoolvanich K: Eosinophilic pleural effusion in adults at Srinagarind Hospital. Southeast Asian J Trop Med Public Health 2003;34:374-378.

22 Ozkara SK, Turan G, Basyigit I: Clinicopathologic significance of eosinophilic pleural effusions in a population with a high prevalence of tuberculosis and cancer. Acta Cytol 2007;51:773-781.

-23 Krenke R, Nasilowski J, Korczynski P, Gorska K, Przybylowski T, Chazan R, et al: Incidence and aetiology of eosinophilic pleura effusion. Eur Respir J 2009;34:1111-1117.
24 Light RW, Erozan YS, Ball WC Jr: Cells in pleural fluid. Their value in differential diagnosis. Arch Intern Med 1973;132:854-860.

25 Hirsch A, Ruffie P, Nebut M, Bignon J, Chretien J: Pleural effusion: laboratory tests in 300 cases. Thorax 1979;34:106-112.

26 Bower G: Eosinophilic pleural effusion. A condition with multiple causes. Am Rev Respir Dis 1967;95:746-751.

27 Brocard H, Broquie G, Blanchon F: The future of eosinophilic pleurisies. Ann Med Interne (Paris) 1973;124:877-882.

28 Campbell GD, Webb WR: Eosinophilic pleural effusion: a review with the presentation of seven new cases. Am Rev Respir Dis 1964;90: 194-201.

29 Filip A, Dobre V: Eosinophilic pleurisy (a study of 27 cases). Pneumoftiziologia 1996; 45:127-130.

30 Martensson G, Pettersson K, Thiringer G: Differentiation between malignant and nonmalignant pleural effusion. Eur J Respir Dis 1985;67:326-334

-31 Maher GG, Berger HW: Massive pleural effusion: malignant and nonmalignant causes in 46 patients. Am Rev Respir Dis 1972;105: 458-460.

32 Ferrer J, Roldan J, Teixidor J, Pallisa E, Gich I, Morell F: Predictors of pleural malignancy in patients with pleural effusion undergoing thoracoscopy. Chest 2005;127:1017-1022.

33 Porcel JM, Vives M: Etiology and pleural fluid characteristics of large and massive effusions. Chest 2003;124:978-983.

34 Morelock SY, Sahn SA: Drugs and the pleura. Chest 1999;116:212-221.

35 Gibson J, Geddes D, Costabel U, Sterk P, Corrin B: Respiratory Medicine, ed 3. London, Saunders, 2003.

36 Albert RK, Spiro SG, Jett JR: Clinical Respiratory Medicine, ed 3. Philadelphia, Mosby/ Elsevier, 2008 